\title{
Impacts of Interpersonal Interaction on Creative Performance: The Moderating Effect of Goal Orientation
}

\author{
Chao-Chan Wu ${ }^{1}$, Fei-Chun Cheng ${ }^{2 *}$ and Wan-Yu Hsieh ${ }^{3}$
}

\begin{abstract}
This study adopted a social perspective to explore the relationships of interpersonal interaction on creative performance and the moderating effect of goal orientation based on the social exchange theory and social capital theory. Interpersonal interaction was divided into two types, expressive relations and instrumental relations. Goal orientation was differentiated as learning goal orientation and performance goal orientation. Creative performance was divided into three facets, namely creative thinking, creative proposals, and creative applications. Data were collected from research and development engineers. The results show that expressive relations have positive effects on all aspects of creative performance, whereas instrumental relations have positive effects on creative applications. Learning goal orientation moderates the relationship between instrumental relations and creative proposals. Performance goal orientation has moderating effects on the relationship between interpersonal relations (both expressive and instrumental) and creative performance. This study addresses a gap in research into types of interpersonal interaction and goal orientation as these relate to creative performance.
\end{abstract}

Keywords: Interpersonal interaction, Goal orientation, Creative performance.

\footnotetext{
${ }^{1}$ Department of Cooperative Economics and Social Entrepreneurship, Feng Chia University, Taichung, Taiwan.

2* Bachelor's Program of Business, Feng Chia University, Taichung, Taiwan.

${ }^{3}$ Department of Cooperative Economics and Social Entrepreneurship, Feng Chia University, Taichung, Taiwan.
}

Article Info: Received: October 20, 2021. Revised: November 15, 2021.

Published online: November 24, 2021. 


\section{Introduction}

Globalization in the business industry, alongside the rapid development of technology and the knowledge economy, has led to increasing risks and competition pressure for enterprises and organizations. To respond to the strategic imitation adopted by competitors, organizations must continue to innovate and generate novel ideas (Tsai, 2011). Corporate innovation originates from the creativity or innovation of employees. Therefore, employee creativity is the foundation of organizational creativity and innovation (Amabile, 1988). Because employee creativity helps corporations and organizations respond to rapidly changing environments, it is receiving growing attention from scholars (Shalley \& Zhou, 2008). However, the evaluation process of creative idea is not abundant enough in the field. Researchers were suggested to pay more attention about the process of creativity evaluation (Wang et al, 2020).

Shalley and Zhou (2008) divided creativity into general creativity (e.g., creativity of children or artwork) and workplace creativity demonstrated by employees. According to aspects of employee behavior and output, workplace creativity can be further divided into creative performance behavior and creative performance outcome. These differ in that creative performance behavior occurs before creative outcomes; hence, creative performance behavior is an antecedent of creative outcomes (Montag, Maertz, \& Baer, 2012). The early model of creativity proposed by Amabile (1988) considers creative performance an outcome of continual operations at different stages. However, previous studies on creativity have rarely distinguish or verified creative performance yielded at different operation stages or facets. Therefore, this study divided creative performance into three facets to perform this verification and to contribute to filling research gaps in relevant fields. Early studies on creativity mostly focused on personal traits, such as the effects of personality and motivation (Park et al. 2013). Recently, a growing number of scholars have paid attention to the effect of social factors on creativity and posited that social networks exert a notable effect (Perry-Smith, 2006; Perry-Smith, 2014). Social networks are considered a crucial element by Western psychologists who study interpersonal interaction and exchange models. Similarly, ethnic Chinese scholars have explored guanxi, or social networks, since the 1980's (Chou, 2007). Because individuals cannot survive alone in society, interpersonal relations and interaction are topics that merit exploration. Individuals can satisfy their needs by interacting with others. Maslow (1943) identified various needs, including survival, safety, social, self-esteem, and self-realization needs. These needs can be fulfilled more easily through interpersonal interaction. Such interaction also facilitates knowledge sharing and experience acquisition. A positive relationship between knowledge and creative performance has been reported (Amabile \& Gryskiewicz, 1987). Therefore, the creative performance of employees might be affected by their interpersonal interaction. However, this topic has received little attention from scholars, and therefore, a research gap remains to be explored. Based on the concept of interpersonal relations orientation, this study divided interpersonal interaction 
into those oriented toward expressive and instrumental relations. Accordingly, how the orientations of interpersonal interaction affect creative performance was explored to supplement the gap in relevant studies on interpersonal interaction and to contribute to literature related to creative performance.

Goal orientation is an essential variable in discussions of creative performance. Numerous studies have explored the effect of goal orientation on creative performance or behavior (e.g., Gong et al., 2009; Bell \& Kozlowski, 2002; Redmond et al., 1993; Tsai, 2011) but acquired inconsistent results. In general, goal orientations are divided into learning and performance goal orientations. In this study, these two types of orientations were used as moderating variables to explore and verify the effect of interpersonal interaction on creative performance. The study results can serve as a reference to address inconsistencies in previous studies.

With the aforementioned assertions, then, this study had three objectives. First, a literature review was performed to clarify the difference between creativity and creative performance and to identify facets of creative performance. Second, from the perspective of social interaction, the study explored the effect of interpersonal interaction on creative performance. Finally, an investigation was conducted into the roles of learning and performance goal orientations in the effect of interpersonal interaction on creative performance.

\section{Literature Review}

\subsection{Orientations of Interpersonal Relations and Interpersonal Interaction}

Interpersonal interaction refers to the behavioral patterns of individuals or specific groups of people who communicate or become involved with one another. The relationships established during social interaction between people are called interpersonal relations (Chang, 1998). Again, social networks are considered crucial by Western psychologists who study interpersonal interaction and exchange models, and ethnic Chinese scholars explore guanxi (Chou, 2007). By the end of the 1990's, Western and Eastern scholars had established various schools of thought regarding social networks, which became a popular topic among researchers (Heath, 2001; Lin \& Chiu, 2004).

A scholar in the ethnic Chinese academic community, Huang (1988) used social exchange theory as a foundation and posited that guanxi is a crucial consideration of Chinese people when they exchange resources. People interact with one another under principles based on three types of relations, namely expressive, mixed, and instrumental relations. In expressive relations, such as those between family members or close friends, people usually endeavor to fulfill each other's needs, such as needs for attention, sympathy, or a sense of safety or belonging. In instrumental relations, such as those between strangers or between bus drivers and passengers, a principle of fairness is established to govern interaction, which is calculative but based on utilitarianism. In mixed relations, such as those between relatives, between teachers and students, or between colleagues, a principle of favor predominates, and people interact through reciprocity to maintain relationships. Yang (1999) asserted 
that interpersonal relations are expressive or instrumental according to whether interaction is based on benefits or affection. This approach involves the following assumptions: (1) All interpersonal relations have two facets, namely instrumental and expressive exchanges. (2) Instrumental and expressive exchanges follow different principles of interaction but are convertible. (3) Under different scenarios, an interaction might involve differing proportions of instrumental exchange and expressive exchange.

To understand the facets of interpersonal relations in organizations, Wu (2003) divided such relations into instrumental and expressive relations. This approach is similar to that proposed by Huang (1983). In expressive relations, organization members endeavor to maintain harmony and view the organization as a large family to build trust and integrate personal goals with organizational goals. In instrumental relations, doing someone a favor is considered an instrument to achieving a goal, and people tend to bring others into their own social networks (Teng, 2007). Therefore, how organization members view their interaction with other members forms interpersonal relations with different orientations. According to discussion in related literature, this study divided interpersonal relations into expressive and instrumental relations.

\subsection{Creative Performance}

The concept of creative performance is similar to that of creativity; consequently, they are easily confused. Creative performance refers to employees' novel or original ideas that can be applied to create products, concepts, or procedures that are relevant or useful to an organization (Oldham \& Cummings, 1996). Early scholars such as Amabile (1988) posited that creativity is the generation of novel and useful products, thoughts, methods, procedures, or services. Creativity is commonly divided into general creativity (that of children or of works of art) or the workplace creativity demonstrated by employees (Shalley \& Zhou, 2008).

Again, topics related to creative performance and creativity are receiving growing attention. A recent study clarified relevant concepts and asserted that creativity is multifaceted (Montag et al., 2012). According to employee behavior and output, workplace creativity can be divided into creative performance behavior and creative performance outcomes. They differ in that creative performance behavior occurs before creative performance outcomes; thus, creative performance behavior is the antecedent. Such behavior helps stakeholders create novel and useful ideas, prototypes, and products and can be either observable or unobservable (Montag et al., 2012). Employees can control their creative performance behavior, whereas their creative performance outcomes might be affected by uncontrollable external factors (Montag et al., 2012). Therefore, this study focused specifically on the behavior in creative performance.

Scholars who have explored topics related to creative performance include George \& Zhang (2001), who discussed the relationship between personal traits and creative behavior. Although creative behavior includes the generation of novel ideas, 
promotion of creative content, and execution of creative projects, it was considered a single construct in their study for exploring the relationships of different variables. Employee creativity is defined as the act of creating novel products and applications or applying new ideas to products or services, ideas that contribute to the innovation, efficient operation, and operation of the organization (Amabile 1983; Gupta \& Singh, 2014). Therefore, creative performance behavior can be explored using the constructs of thought and application. Montag et al. (2012) reviewed SSCI papers related to creativity and innovation models. They reported that the five most cited papers considered creative performance behavior a multifaceted concept. Basadur (1994) divided creative performance into two constructs whereas, from the perspective of procedure, Gupta \& Singh (2014) divided it into four constructs, namely problem identification, information search, idea generation, and idea promotion. This indicates the theoretical significance of dividing creative performance into various constructs when conducting related research.

\subsection{Relationship between Interpersonal Relations and Creative Performance}

Social capital theory emphasizes the importance of social networks. When individuals interact with others and establish unique social relations, they can acquire resources or information. Therefore, social capital exists in social networks (Adler \& Kwon, 2002). Tsai \& Ghoshal (1998) asserted that when members of a team establish a tight social network, they can more easily exchange and compile information and resources, which in turn positively affect product innovation and value creation. Therefore, social networks serve as a means of collaboration for internal and external network members to share knowledge and techniques, helping them create new knowledge, share experience, and continually improve work performance (Argyris \& Schon, 1978).

Hulsheger et al. (2009) indicated that interaction among team members forms a knowledge network. Thus, a knowledge network is formed by relations between individuals, and information or knowledge possessed by individuals circulates through their social networks. Therefore, experience and knowledge shared through social interaction can induce the formation of new knowledge and perspectives, which leads to the generation of new ideas. Ipe (2003) asserted that the interaction of individuals in different levels of an organization facilitates the generation of knowledge. Other scholars have indicated that the enhancement of knowledge and techniques leads to creative production (Amabile \& Gryskiewicz, 1987). Therefore, the interpersonal interaction of individuals promotes the sharing and exchange of information and knowledge to drive new ideas or discoveries and improve creative performance.

From the perspective of interpersonal personal orientations, this study explored the effect of interpersonal relations on creative performance and defined the orientations of such relations as either expressive or instrumental. Expressive interaction refers to organizational members maintaining harmony to the best of 
their ability. In such interaction, the members build trust among one another and align personal goals with organizational goals. Therefore, interpersonal interaction with an expressive orientation is likely to elicit a sense of encouragement in the interacting members. Creative performance is often achieved through highly stressful and risky activities. Expressive interaction among colleagues can not only encourage them to work more efficiently but also improve their creative performance due to the sharing of knowledge and techniques through emotional ties. In instrumental interaction, doing someone a favor is considered a social tool. To achieve their goals, individuals establish relationships with others and bring others into their own social networks. Therefore, people tend to seek help through instrumental interaction when encountering difficulty in life or at work. In addition, through interacting with others to solve problems, employees might acquire professional knowledge and thereby improve their creative performance. In this study, creative performance was divided into three constructs, namely creative thinking, proposals, and applications. Accordingly, the following hypotheses were proposed:

H1: Expressive relations in interpersonal interaction positively affect creative performance.

H1a: Expressive relations in interpersonal interaction positively affect creative thinking.

H1b: Expressive relations in interpersonal interaction positively affect creative proposals.

H1c: Expressive relations in interpersonal interaction positively affect creative applications.

$\mathrm{H} 2$ : Instrumental relations in interpersonal interaction positively affect creative performance.

H2a: Instrumental relations in interpersonal interaction positively affect creative thinking.

$\mathrm{H} 2 \mathrm{~b}$ : Instrumental relations in interpersonal interaction positively affect creative proposals.

$\mathrm{H} 2 \mathrm{c}$ : Instrumental relations in interpersonal interaction positively affect creative applications.

\subsection{Goal Orientation}

Goal orientation theory originated in achievement motivation theory in educational psychology. Goal orientation refers to the various behavioral orientations demonstrated by individuals learning to achieve goals (Dweck, 1986). When they are aiming to achieve a goal, the motivation of learners can be divided into learning goal orientation and performance goal orientation (Dweck, 1986; Dweck \& Leggett, 1988). Learning goal orientation stresses learning new knowledge, techniques, behavior, or strategies. Individuals who are learning goal-oriented focus on the process of learning and attempt to identify approaches to achieving preset goals. Therefore, they are likely to accept difficult missions to improve (Dweck, 1986). 
Individuals who are performance goal-oriented seek positive feedback on their attempts and avoid negative feedback. Such individuals believe that personal ability remains constant and that success depends on innate ability. Therefore, they aim to receive positive feedback from others and tend to avoid negative feedback and failure to prevent damage to their self-esteem (Dweck, 1986; Dweck \& Leggett, 1988). When performance goal-oriented individuals perceive that they do not possess sufficient ability to complete a learning task, they tend to shy away from the task or give up easily (Elliott \& Dweck, 1988).

In early work, learning goal and performance goal orientations were considered different achievement motivations. They were considered the two extremes of a continuum (Vande Walle, 1997). More recent research has revealed that learning goal and performance goal orientations are not opposites; instead, they are two independent constructs. This is because individuals might endeavor to improve their ability while attempting to achieve more favorable performance (Button et al., 1996; Farr et al., 1993; Bell \& Kozlowski, 2002; Chen \& Chen, 2006).

Researchers have posited that the enhancement of knowledge and techniques is conducive to creative production (Amabile \& Gryskiewicz, 1987). Knowledge and techniques are acquired mainly through learning. Therefore, this study explored goal orientations during learning processes to examine the effect of learning on factors of creative performance.

\subsection{Moderating Effect of Goal Orientation on the Relationship Between Interpersonal Relations and Creative Performance}

Goal orientation plays an important role as individuals pursue performance outcomes (Simmons, A.L., \& Ren, R., 2009). Studies have yielded inconsistent results regarding the effect of learning goal orientation on creative performance. For example, Gong et al. (2009) indicated that learning goal orientation affects creative performance over time. Bell \& Kozlowski (2002) demonstrated a positive correlation between learning goal orientation and performance, whereas Redmond et al. (1993) reported a nonsignificant relationship between learning goal orientation and creative performance. Tsai (2011) explored the effects of transformational leadership, learning goal orientation, and performance goal orientation on creative behavior and rejected the hypothesis that learning goal orientation affects creative behavior. However, the interaction effect of learning goal orientation and performance goal orientation was observed to affect creative behavior. Accordingly, we inferred that goal orientation does not influence creative performance through a main effect. Instead, it moderates the relationship between interpersonal relations and creative performance.

Individuals who are highly learning goal-oriented tend to undertake highly challenging tasks and bear the corresponding risks. When facing obstacles, they tend to work harder (Shalley et al., 2000) to acquire knowledge and techniques in relevant fields and improve their performance (Dweck, 1986). When organization members engage in expressive interaction, they trust one another and align their 
personal goals with organizational goals. Therefore, when such members face difficulties or risks and are learning goal-oriented individuals who are willing to take risks, they can identify solutions through expressive interaction with other members and thereby improve their creative performance. Innovative behavior is accompanied by higher risks and likelihood of failure compared with routine tasks. During the process of innovation, individuals are more likely to be challenged by others and be required to overcome obstacles (Huang \& Huang, 2006). Therefore, when organization members encounter difficulty and risks while attempting to fulfill organizational goals related to creative performance, highly learning goaloriented individuals who are willing to face challenges can engage in expressive interaction with other members to receive encouragement or share knowledge, thus improving their creative performance.

Individuals with high learning goal orientation believe that personal ability can be developed. Thus, such individuals continually attempt to improve their ability, refine their skills through learning, and adopt effective learning strategies (Dweck, 1986), allowing them to acquire knowledge more efficiently. When organization members interact with others and share knowledge, highly learning goal-oriented individuals are more effective in acquiring information or knowledge through interpersonal interaction because of their interest in learning. This enables such individuals to improve their creative performance.

Janssen and Van Yperen (2004) asserted that employees with high learning goal orientation have higher intrinsic motivation when undertaking assignments (Tsai, 2011). Intrinsic motivation theory states that employees with high intrinsic motivation tend to work harder. When employees actively engage in work, their attention is completely focused, allowing them to identify desirable approaches to completing their tasks. They also continue to acquire knowledge and experience when interacting with other employees. This in turn strengthens the relationship between knowledge sharing and creative performance. In sum, learning goaloriented individuals believe that personal growth is achievable in learning and therefore exhibit intrinsic motivation to learn. When they encounter difficulty at work, such learning motivation prompts them to acquire new knowledge and thus improve creative performance.

Accordingly, learning goal orientation strengthens the effect of expressive interaction on creative performance. Therefore, the following hypotheses were proposed:

H3: Learning goal orientation moderates the relationship between expressive relations and creative performance; high learning goal orientation strengthens the positive relationship between expressive interaction and creative performance.

H4: Learning goal orientation moderates the relationship between instrumental relations and creative performance; high learning goal orientation strengthens the positive relationship between instrumental interaction and creative performance. 
Individuals with different goal orientations exhibit distinct response patterns. Employees with performance goal orientation aim to prove their superiority over others and perceive the work performance required by the organization as the standard for competition. This prompts them to strive to achieve the required performance, earn recognition from supervisors, and acquire more favorable assessment scores and feedback (Steele-Johnson et al., 2000). Performance goaloriented employees focus on competing against and surpassing other employees (Janssen \& Van Yperen, 2004).

Studies have reported inconsistent results regarding the effect of performance goal orientation on creative performance. For example, Bell and Kozlowski (2002) revealed a negative correlation between performance goal orientation and creative performance, whereas Janssen \& Van Yperen (2004) observed a nonsignificant correlation between them. We inferred that performance goal also serves as a moderator between interpersonal interaction and knowledge sharing. Specifically, because performance goal-oriented individuals want to demonstrate superiority, they pay close attention to the creative performance of others when interacting with them. This motivates such individuals to improve their own performance and consequently strengthens the relationship between interpersonal relations and creative performance. Accordingly, the following hypotheses were proposed:

H5: Performance goal orientation moderates the relationship between expressive relations and creative performance; high performance goal orientation strengthens the positive relationship between expressive interaction and creative performance.

H6: Performance goal orientation moderates the relationship between instrumental relations and creative performance; high performance goal orientation strengthens the positive relationship between instrumental interaction and creative performance.

\section{Methods}

This study explored the influences of expressive and instrumental relations on creative performance as well as the moderating effect of goal orientation governing these influences.

\subsection{Research Framework}

According to the research objectives and our review of the literature, we investigated the relationship between interpersonal relations and creative performance. Expressive and instrumental relations were independent variables, learning and performance goal orientations were moderating variables, and creative performance was the dependent variable. Figure 1 illustrates the research framework. 


\subsection{Participants and Data Collection}

An anonymous questionnaire was distributed to research and development engineers in 24 technology companies located in Hsinchu and Taichung, Taiwan.

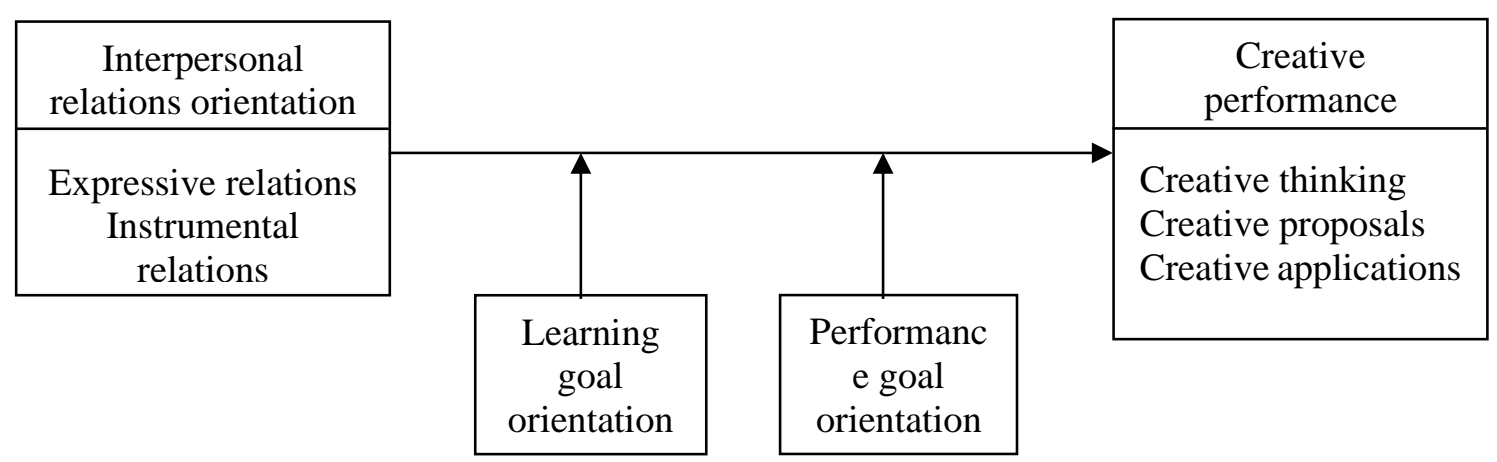

Figure 1: Research framework

The collected data were then used to conduct empirical analysis. Before completing the questionnaire, the participants were informed that the collected data were strictly for academic research purposes and that no one except the researchers could browse their responses. The collected data were used for comprehensive analysis.

A total of 232 questionnaires were collected. Two with excessive numbers of unanswered items or overly consistent responses were excluded, yielding 230 valid samples and a valid return rate of $99.14 \%$. Of the respondents, 177 were men and 53 were women; 61 were $\leq 30$ years old, 112 were $31-40$ years old, 50 were $41-50$ years old, and 7 were $\geq 51$ years old. Regarding educational attainment level, 1, 115, and 114 respondents selected the option of senior high school or below, college, and graduate school or above, respectively. Regarding years of service, 25 had worked for $<1$ year, 84 for $1-3$ years, 41 for $4-6$ years, 41 for $7-9$ years, and 39 for $\geq 10$ years. In Taiwan, numerous technology companies are located in Hsinchu and Taichung; thus, the samples collected in this study were sufficiently representative.

\subsection{Measurements}

\subsubsection{Interpersonal Relations Orientation}

Interpersonal relations are relationships established through the social behavior of communication and interaction. In a workplace environment, employees might engage in interpersonal interaction of varying orientations. In this study, interpersonal relations were divided into those with expressive or instrumental orientations. According to the questionnaire items created by Wu (2003), a scale was designed with items for expressive and instrumental relations. Specifically, nine items were created for expressive relations; examples include "In this company, colleagues have close relationships, and everyone helps one another out"; and "In this company, colleagues participate in gatherings and events regularly after work." Seven items were designed for instrumental relations; examples include "In this 
company, colleagues treat each other differently depending on the closeness of their relationship"; and "In this company, the rights of employees are jeopardized when they do not establish favorable relationships with others." All items are multiplechoice with a 5-point Likert scale ranging from strongly disagree (1) to strongly agree (5).

Exploratory factor analysis was performed, in which principal axis factoring and oblique rotations were used to identify the two constructs most relevant to the theories discussed in this study. One item with a loading of $<0.5$ was removed to reach a total explained variance of $55.44 \%$. This indicated that the questionnaire had favorable validity. Regarding reliability, the Cronbach's $\alpha$ values of the expressive and instrumental relations items were 0.91 and 0.88 , respectively.

\subsubsection{Goal Orientation}

Goal orientation refers to the motivation orientations demonstrated by individuals during a learning process to achieve particular goals. The goal orientation items were based on the goal orientation scale proposed by Janssen \& Van Yperen (2004), which includes items on learning and performance goal orientations. Eight items were based on learning goal orientation; examples include "During work, I feel a sense of achievement when I see that I have improved"; and "During work, I feel a sense of achievement when I acquire new knowledge and skills." Eight items were based on performance goal orientation; examples include "During work, I feel a sense of achievement when I have the highest performance of all employees"; and "During work, I feel a sense of achievement when I am the most outstanding employee." The scale uses a 7-point Likert scale that ranges from strongly disagree (1) to strongly agree (7).

Following exploratory factor analysis with principal axis factoring and oblique rotations, no item was excluded from the goal orientation scale. The total explained variance was $71.69 \%$, indicating that the scale exhibited favorable validity. The Cronbach's $\alpha$ values of the learning and performance goal orientation items were 0.97 and 0.93 , respectively.

\subsubsection{Creative Performance}

Creative performance denotes creating products, services, processes, or ideas that are novel and useful to an organization. In this study, the creative performance items were based on the 13-item scale proposed by George and Zhou (2001). A 5-point Likert scale was used to determine respondents' agreement with the items. Although studies have indicated that creative performance is a multifaceted concept, the scale did not divide creative performance into multiple constructs.

To further explore the constructs of creative performance, exploratory factory analysis was conducted with principal axis factoring and oblique rotations to identify three factors. The loadings of all items were $>0.4$. However, two items (Items 6 and 13) were excluded because they exhibited cross-loadings, or loadings that were $>0.4$ in at least two factors. According to the content of items in each factor and relevant theories on creative performance, the three constructs of creative 
performance were named "creative thinking" (Items 4, 5, 10, 11, and 12), "creative proposals" (Items 7, 8, and 9), and "creative applications" (Items 1, 2, and 3), totaling 11 items. The total explained variance was $64.03 \%$. The Cronbach's $\alpha$ values of the items in the creative thinking, creative proposals, and creative applications constructs were $0.90,0.85$, and 0.87 , respectively.

Harman's one-factor test was used to investigate for common method variance (Podsakoff and Organ, 1986). The results revealed the absence of a main factor able to explain the covariance of variables. Therefore, common method variance did not exist.

\subsubsection{Control Variables}

The control variables of this study were gender, age, education, and job tenure. Gender was used as a control variable because men and women might develop different thought processes and problem-solving skills that in turn affect their creative performance. Similarly, people of different ages vary in how they think and handle things, and thus, exhibiting varying creative performance. Education, reflecting the level of knowledge attained, may also affect creativity (Gong et al., 2009). Tierndy and Farmer (2002) posited job tenure with an organization might be related to creativity. The control variables were thus selected on the basis of previous findings (Gong et al., 2009; Tierney \& Farmer, 2002; Leung et al., 2014).

\section{Results}

\subsection{Descriptive Statistics and Correlation Analysis}

Table I lists the mean, standard deviation (SD), and correlation coefficients of each variable. The results revealed that expressive and instrumental relations exhibited a moderate-to-low negative correlation $(\mathrm{r}=-0.201, \mathrm{p}<0.05)$. Expressive relations were significantly positively correlated with creative thinking $(r=0.150, p<0.05)$ and proposals $(\mathrm{r}=0.200, \mathrm{p}<0.05)$. Learning goal orientation was significantly positively correlated with creative thinking $(r=0.30, p<0.01)$, proposals $(r=0.343$, $\mathrm{p}<0.01)$, and applications $(\mathrm{r}=0.322, \mathrm{p}<0.01)$. Performance goal orientation was also significantly correlated with creative thinking $(\mathrm{r}=0.317, \mathrm{p}<0.01)$, proposals $(r=0.356, p<0.01)$, and applications $(r=0.284, p<0.01)$. Therefore, both learning and performance goal orientations were significantly correlated with creative performance. 
Table 1: Means, SDs, and correlation coefficients of variables

\begin{tabular}{|c|c|c|c|c|c|c|c|c|c|c|c|c|c|}
\hline Variable & Mean & SD & 1 & 2 & 3 & 4 & 5 & 6 & 7 & 8 & 9 & 10 & 11 \\
\hline Gender & 1.23 & 0.42 & & & & & & & & & & & \\
\hline Age & 2.01 & 0.78 & -.089 & & & & & & & & & & \\
\hline Education & 2.49 & 0.51 & -.123 & -.126 & & & & & & & & & \\
\hline Job tenure & 2.93 & 1.29 & .068 & $.523^{* *}$ & $-.297^{* *}$ & & & & & & & & \\
\hline $\begin{array}{c}\text { Expressive } \\
\text { relations }\end{array}$ & 3.81 & 0.54 & .070 & $-.223^{* *}$ & -.019 & -.095 & $(0.91)$ & & & & & & \\
\hline $\begin{array}{c}\text { Instrumental } \\
\text { relations }\end{array}$ & 3.16 & 0.74 & -.070 & -.057 & .048 & .005 & $-.201^{* *}$ & $(0.88)$ & & & & & \\
\hline $\begin{array}{c}\text { Learning goal } \\
\text { orientation }\end{array}$ & 5.98 & 0.82 & -.030 & -.099 & .103 & $-.141^{*}$ & $.398^{* *}$ & -.127 & $(0.97)$ & & & & \\
\hline $\begin{array}{c}\text { Performance } \\
\text { goal orientation }\end{array}$ & 4.90 & 1.07 & -.019 & $-.147^{*}$ & $.157^{*}$ & -.075 & $.287^{* *}$ & .019 & $.425^{* *}$ & $(0.93)$ & & & \\
\hline $\begin{array}{l}\text { Creative } \\
\text { thinking }\end{array}$ & 3.40 & 0.64 & -.081 & .054 & .076 & -.047 & $.150^{*}$ & .064 & $.299^{* *}$ & $.317^{* *}$ & $(0.90)$ & & \\
\hline $\begin{array}{c}\text { Creative } \\
\text { proposals }\end{array}$ & 3.56 & 0.61 & $-.131^{*}$ & .015 & .059 & -.065 & $.200^{* *}$ & .056 & $.343^{* *}$ & $.356^{* *}$ & $.592^{* *}$ & $(0.85)$ & \\
\hline $\begin{array}{c}\text { Creative } \\
\text { applications }\end{array}$ & 3.63 & 0.63 & -.081 & .075 & .038 & -.047 & .088 & .088 & $.322^{* *}$ & $.284^{* *}$ & $.695^{\text {** }}$ & $.643^{* *}$ & $(0.87)$ \\
\hline
\end{tabular}

Note: Bracketed values denote the internal consistency coefficients.

$* p<0.05, * * p<0.01$ 


\subsection{Confirmatory Factor Analysis}

Before hypothesis validation, AMOS 22 was used to conduct confirmatory factor analysis of creative performance and to verify the statistical fit of the evaluation model. First, the one-factor model was verified (by combining all items into a single construct), followed by verifying the two-factor (i.e., items related to creative thinking were treated as a single group, and items related to the proposal and application of creative ideas were treated as another group) and three-factor models (the theorical model used in this study). Examining the differences between the chisquared values revealed that the three-factor model was more adequate than the onefactor and two-factor models ( $\triangle \chi 2=142.2$ and 234.57, respectively; $\mathrm{p}<0.01$ ). Regarding other fit indexes of the three-factor model, the comparative fit index = 0.948 , normed fit index $=0.926$, root mean square error of approximation $=0.095$, goodness of fit index $=0.907$, and root mean square residual $=0.026$, all of which were within recommended thresholds (Browne \& Cudeck, 1993). This indicated that the model had favorable statistical fit.

For the tested constructs, the loadings of all items were between 0.53 and 0.73 , and the t values were significant ( $\mathrm{p}<0.01$ ), indicating high convergence (Bagozzi \& Yi, 1988). Finally, the average variance extracted for creative thinking, proposals, and applications were determined to be $0.65,0.65$, and 0.69 , respectively. Because all values were greater than 0.5 and the squared coefficients of the constructs, the constructs exhibited favorable discriminant validity (Fornell \& Larcker, 1981).

Table 2: Confirmatory factor analysis of the various constructs of creative performance

\begin{tabular}{|c|c|c|c|c|c|c|c|c|c|}
\hline Compared model & $\chi^{2}$ & $\mathrm{df}$ & $\chi^{2} / \mathrm{df}$ & $\Delta \chi^{2}$ & CFI & NFI & RMSEA & GFI & RMR \\
\hline One-factor model & 361.91 & 44 & 8.23 & & 0.81 & 0.79 & 0.177 & 0.74 & 0.042 \\
\hline Two-factor model & 219.71 & 43 & 5.11 & $142.2^{* *}$ & 0.89 & 0.87 & 0.133 & 0.84 & 0.033 \\
\hline $\begin{array}{c}\text { Three-factor model } \\
\text { (used in this study) }\end{array}$ & 127.34 & 41 & 3.11 & $234.57 * *$ & 0.948 & 0.926 & 0.095 & 0.907 & 0.026 \\
\hline
\end{tabular}

Note 1: $* * p<0.01$

Note 2: $\Delta \chi^{2}$ denotes the comparison results for the one-factor model and other models.

\subsection{Moderating Effect of Goal Orientation on the Relationship between Interpersonal Relations and Creative Performance}

Multiple Regression was used to explore the effects of expressive and instrumental relations on creative performance and to examine the role of goal orientation. Four steps were adopted to verify the main and moderating effects in these relationships. First, all control variables (i.e., gender, age, education, and Job tenure) were incorporated into the regression model. Second, the independent variables (i.e., expressive and instrumental relations) were incorporated into the regression model. Third, the moderating variables (i.e., learning and performance goal orientations) were incorporated into the regression model. Finally, the interaction terms of the 
independent and moderating variables were incorporated into the regression model. These terms were expressive relations $\times$ learning goal orientation; instrumental relations $\times$ learning goal orientation; expressive relations $\times$ performance goal orientation; and instrumental relations $\times$ performance goal orientation. The interaction terms were centered before being incorporated into the regression model to alleviate the problem of multicollinearity (Jaccard et al., 1990).

Because creative performance was divided into three constructs (i.e., creative thinking, proposals, and applications), they were analyzed separately. The results revealed that expressive relations positively predicted creative thinking $(\beta=0.186$, $\mathrm{p}<0.05$; Table III; Step 2), whereas instrumental relations were not significantly correlated with this construct. Therefore, H1a was supported, and H2a was rejected. Expressive relations positively predicted creative proposals $(\beta=0.23, p<0.05$; Table IV; Step 2), whereas instrumental relations were not significantly correlated with this construct. Therefore, $\mathrm{H} 1 \mathrm{~b}$ was supported, and $\mathrm{H} 2 \mathrm{~b}$ was rejected.

Both expressive $(\beta=0.12)$ and instrumental $(\beta=0.12)$ relations affected creative applications at a significance level of $\mathrm{p}<0.1$ (Table V, Step 2). Therefore, H1c and $\mathrm{H} 2 \mathrm{c}$ were supported. Overall, $\mathrm{H} 1$ was fully supported, and $\mathrm{H} 2$ was partially supported.

Next, the moderating effects were explored. The results indicated that the interaction term between expressive relations and learning goal orientation exerted nonsignificant effects on creative proposals (Table III, Step 4) and creative applications (Table V, Step 4). The regression coefficients of the interaction term between expressive relations and learning goal orientation were nonsignificant, as were those between instrumental relations and learning goal orientation. Regarding creative proposals (Table IV, Step 4), the interaction term between expressive relations and learning goal orientation exerted a nonsignificant effect, whereas the regression coefficient of the interaction term between instrumental relations and learning goal orientation was significant at $\mathrm{p}<0.1(\beta=-0.125)$. Therefore, H3 was rejected, and $\mathrm{H} 4$ was partially supported for creative proposals.

The regression coefficients of the interaction term between expressive relations and performance goal orientation were significant (creative thinking, $\beta=0.309, p<0.01$; creative proposals, $\beta=0.253, \mathrm{p}<0.01$; creative applications, $\beta=0.295, \mathrm{p}<0.01$ ). Therefore, H5 was supported. The regression coefficients of the interaction term between instrumental relations and performance goal orientation were also significant (creative thinking, $\beta=0.17, p<0.05$; creative proposals, $\beta=0.216, p<$ 0.01 ; creative applications, $\beta=0.253, \mathrm{p}<0.01$ ). Therefore, H6 was supported. 
Table 3: Regression of interpersonal relations, goal orientation, and creative thinking

\begin{tabular}{|c|c|c|c|c|}
\hline & \multicolumn{4}{|c|}{ Creative Performance 1: Creative Thinking } \\
\hline Variable & Step 1 & Step 2 & Step 3 & Step 4 \\
\hline \multicolumn{5}{|c|}{ Control Variable } \\
\hline Gender & -.060 & -.060 & -.047 & -.050 \\
\hline Age & .096 & $.149 \dagger$ & $.162 *$ & $.151 *$ \\
\hline Education & .058 & .060 & .007 & .009 \\
\hline Job tenure & -.076 & -.086 & -.078 & -.035 \\
\hline \multicolumn{5}{|c|}{ Independent Variable } \\
\hline Expressive Relations & & $.186^{*}$ & .049 & .085 \\
\hline Instrumental Relations & & .103 & .099 & .045 \\
\hline \multicolumn{5}{|c|}{ Moderating Variable } \\
\hline Learning Goal Orientation & & & $.187^{*}$ & .141 \\
\hline Performance Goal Orientation & & & $.235 * *$ & .238 \\
\hline \multicolumn{5}{|c|}{\begin{tabular}{|c|} 
Interaction Term \\
\end{tabular}} \\
\hline $\begin{array}{l}\text { Expressive Relations } \times \text { Learning } \\
\text { Goal Orientation }\end{array}$ & & & & -.079 \\
\hline $\begin{array}{l}\text { Expressive Relations } \times \text { Performance } \\
\text { Goal Orientation }\end{array}$ & & & & $.309 * *$ \\
\hline $\begin{array}{l}\text { Instrumental Relations } \times \text { Learning } \\
\text { Goal Orientation }\end{array}$ & & & & -.005 \\
\hline $\begin{array}{l}\text { Instrumental Relations } \times \\
\text { Performance Goal Orientation }\end{array}$ & & & & $.170^{*}$ \\
\hline Model F & 1.036 & $2.085 \dagger$ & $5.161^{* *}$ & $5.496 * *$ \\
\hline $\mathrm{R}^{2}$ & 0.018 & 0.053 & 0.157 & 0.233 \\
\hline$\Delta \mathrm{R}^{2}$ & & 0.035 & 0.104 & 0.076 \\
\hline
\end{tabular}

Note: Regression coefficients are standardized.

$\dagger \mathrm{P}<0.1, * \mathrm{P}<0.05, * * \mathrm{P}<0.01$ 
Table 4: Regression of interpersonal relations, goal orientation, and creative proposals

\begin{tabular}{|c|c|c|c|c|}
\hline \multirow{2}{*}{\begin{tabular}{|l|} 
Variable \\
\end{tabular}} & \multicolumn{4}{|c|}{ Creative Performance 2: Creative Proposals } \\
\hline & Step 1 & Step 2 & Step 3 & Step 4 \\
\hline \multicolumn{5}{|c|}{ Control Variable } \\
\hline Gender & $-.119 \dagger$ & $-.121 \dagger$ & $-.106 \dagger$ & $-.106 \dagger$ \\
\hline Age & .046 & .109 & $.122 \dagger$ & .102 \\
\hline Education & .029 & .033 & -.025 & -.033 \\
\hline Job tenure & -.073 & -.082 & -.074 & -.034 \\
\hline \multicolumn{5}{|c|}{ Independent Variable } \\
\hline Expressive Relations & & $.230 * *$ & .081 & .074 \\
\hline Instrumental Relations & & .098 & .095 & .078 \\
\hline \multicolumn{5}{|c|}{ Moderating Variable } \\
\hline Learning Goal Orientation & & & $.207 * *$ & $.222 * *$ \\
\hline Performance Goal Orientation & & & $.254 * *$ & $.250 * *$ \\
\hline \multicolumn{5}{|c|}{\begin{tabular}{|c|} 
Interaction Term \\
\end{tabular}} \\
\hline $\begin{array}{l}\text { Expressive Relations } \times \text { Learning } \\
\text { Goal Orientation }\end{array}$ & & & & -.039 \\
\hline $\begin{array}{l}\text { Expressive Relations } \times \\
\text { Performance Goal Orientation }\end{array}$ & & & & $.253 * *$ \\
\hline $\begin{array}{l}\text { Instrumental Relations } \times \text { Learning } \\
\text { Goal Orientation }\end{array}$ & & & & $-.125 \dagger$ \\
\hline $\begin{array}{l}\text { Instrumental Relations } \times \\
\text { Performance Goal Orientation }\end{array}$ & & & & $.216^{* *}$ \\
\hline Model F & 1.306 & $2.916 * *$ & $6.783 * *$ & $6.39 * *$ \\
\hline $\mathrm{R}^{2}$ & 0.151 & 0.27 & 0.444 & 0.511 \\
\hline$\Delta \mathrm{R}^{2}$ & & 0.119 & 0.174 & 0.067 \\
\hline
\end{tabular}

Note: Regression coefficients are standardized.

$\dagger p<0.1, * p<0.05, * * p<0.01$ 
Table 5: Regression of interpersonal relations, goal orientation, and creative applications

\begin{tabular}{|c|c|c|c|c|}
\hline \multirow[b]{2}{*}{ Variable } & \multicolumn{4}{|c|}{ Creative Performance 3: Creative Applications } \\
\hline & Step 1 & Step 2 & Step 3 & Step 4 \\
\hline \multicolumn{5}{|c|}{ Control Variable } \\
\hline Gender & -.060 & -.056 & -.041 & -.042 \\
\hline Age & .127 & $.166^{*}$ & $.173 *$ & $.154 *$ \\
\hline Education & .015 & .015 & -.039 & -.044 \\
\hline Job tenure & -.105 & -.115 & -.099 & -.054 \\
\hline \multicolumn{5}{|c|}{ Independent Variable } \\
\hline Expressive Relations & & $.120 \dagger$ & -.034 & -.028 \\
\hline Instrumental Relations & & $.116 \dagger$ & $.119 \dagger$ & .084 \\
\hline \multicolumn{5}{|c|}{ Moderating Variable } \\
\hline Learning Goal Orientation & & & $.259 * *$ & $.236 * *$ \\
\hline Performance Goal Orientation & & & $.200 * *$ & $.196 * *$ \\
\hline \multicolumn{5}{|c|}{\begin{tabular}{|c|} 
Interaction Term \\
\end{tabular}} \\
\hline $\begin{array}{l}\text { Expressive Relations } \times \text { Learning Goal } \\
\text { Orientation }\end{array}$ & & & & -.076 \\
\hline $\begin{array}{l}\text { Expressive Relations } \times \text { Performance } \\
\text { Goal Orientation }\end{array}$ & & & & $.295^{* *}$ \\
\hline $\begin{array}{l}\text { Instrumental Relations } \times \text { Learning Goal } \\
\text { Orientation }\end{array}$ & & & & -.059 \\
\hline $\begin{array}{l}\text { Instrumental Relations } \times \text { Performance } \\
\text { Goal Orientation }\end{array}$ & & & & $.253 * *$ \\
\hline Model F & 1.147 & $1.591 * *$ & $5.383^{* *}$ & $5.854 * *$ \\
\hline $\mathrm{R}^{2}$ & 0.141 & 0.203 & 0.404 & 0.495 \\
\hline$\Delta \mathrm{R}^{2}$ & & 0.062 & 0.201 & 0.091 \\
\hline
\end{tabular}

Note: Regression coefficients are standardized.

$\dagger p<0.1, * p<0.05, * * p<0.01$

According to the suggestion of Aiken \& West (1991), interaction effect graphs were plotted by dividing the participants into high- and low-score groups according to \pm 1 SD of the goal orientation scores. Figures 2, 3, and 4 present the interaction effect graphs for creative thinking, proposals, and applications, respectively. The results revealed that individuals with high and low performance goal orientation exhibited different relationships between expressive relations and creative thinking. Specifically, highly performance goal-oriented individuals exhibited a positive 
relationship between expressive relations and creative thinking, whereas low performance goal-oriented individuals exhibited a negative relationship (Figure 2a). Similarly, highly performance goal-oriented individuals exhibited a positive relationship between instrumental relations and creative thinking, whereas low performance goal-oriented individuals exhibited a negative relationship (Figure 2b). Figure 3 a illustrates the interaction effect of expressive relations $\times$ performance goal orientation on creative proposals, and Figure $3 \mathrm{~b}$ illustrates the interaction effect of instrumental relations $\times$ performance goal orientation on creative proposals. The results revealed that in highly performance goal-oriented individuals, expressive and instrumental relations exhibited positive relationships with creative proposals. Figure $3 \mathrm{c}$ illustrates the interaction effect of instrumental relations $\times$ learning goal orientation on creative proposals. The results indicated that highly learning goaloriented individuals demonstrated more favorable performance in proposing creative ideas than did low learning goal-oriented individuals. For individuals with low learning goal orientation, those with a high instrumental relations score demonstrated more favorable performance in proposing creative ideas than did those with a low instrumental relations score.

Figure 4a illustrates the interaction effect of expressive relations $\times$ performance goal orientation on creative applications. Figure $4 \mathrm{~b}$ illustrates the effect of instrumental relations $\times$ performance goal orientation on creative applications. The results revealed that in highly performance goal-oriented individuals, expressive and instrumental relations were positively correlated with creative applications. In individuals with low performance goal orientation, both expressive and instrumental relations were negatively correlated with creative applications; however, the negative correlation exhibited for instrumental relations was less noticeable.

Interaction effect graphs were also plotted to further examine the moderating effect of learning and performance goal orientations on the relationship between interpersonal relations and creative performance. Overall, expressive relations were negatively correlated with creative thinking and proposals in individuals with low performance goal orientation. In individuals with high performance goal orientation, both expressive and instrumental relations enhanced creative thinking, proposals, and applications. Additionally, learning goal orientation enhanced the relationship between low instrumental relations and creative proposals. 


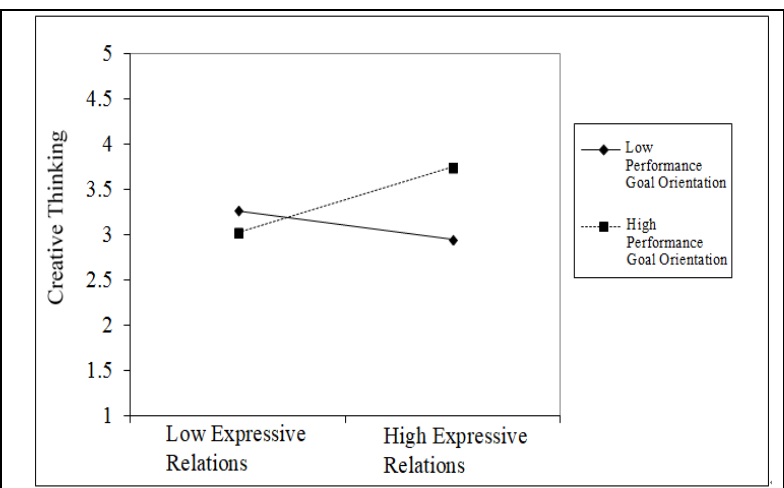

Figure 2a. Interaction effect graph of expressive relations, performance goal orientation, and creative thinking

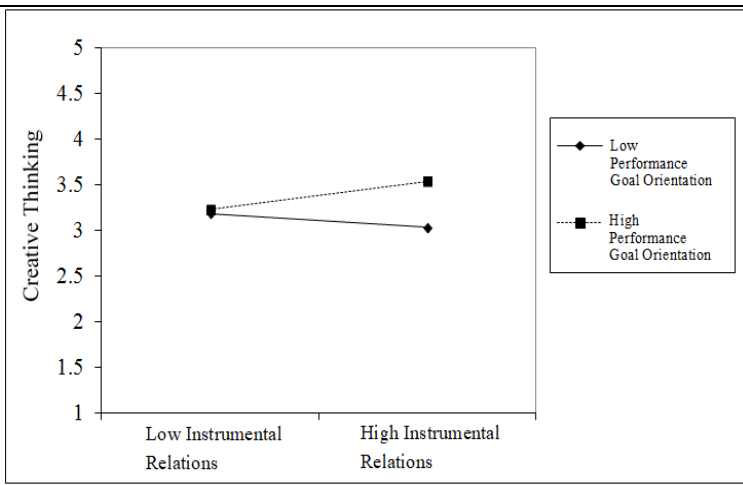

Figure $2 b$. Interaction effect graph of instrumental relations, performance goal orientation, and creative thinking

Figure 2: Interaction effect graph of interpersonal relations, performance goal orientation, and creative thinking

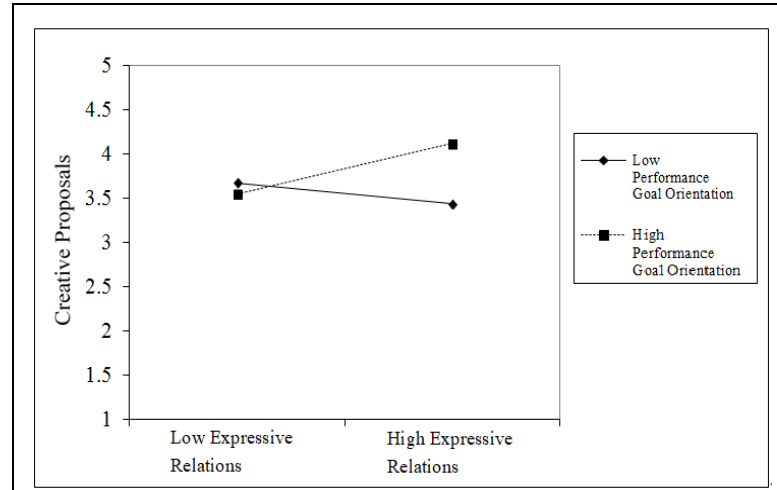

Figure 3a. Interaction effect graph of expressive relations, performance goal orientation, and creative proposals

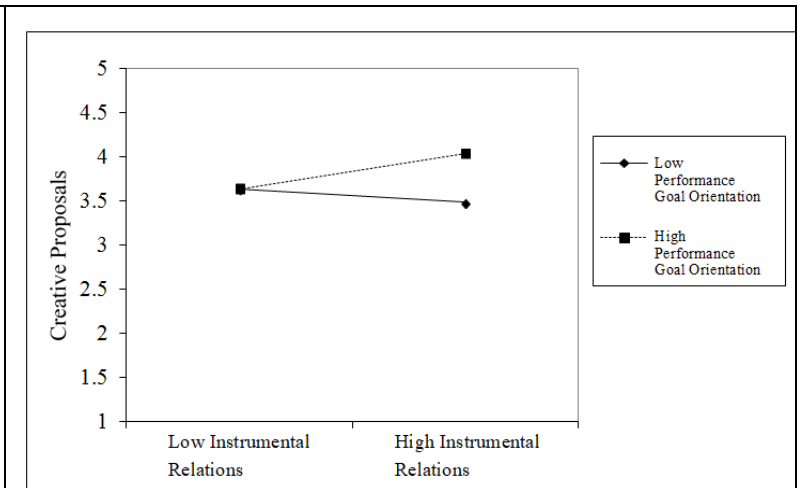

Figure $3 b$. Interaction effect graph of instrumental relations, performance goal orientation, and creative proposals

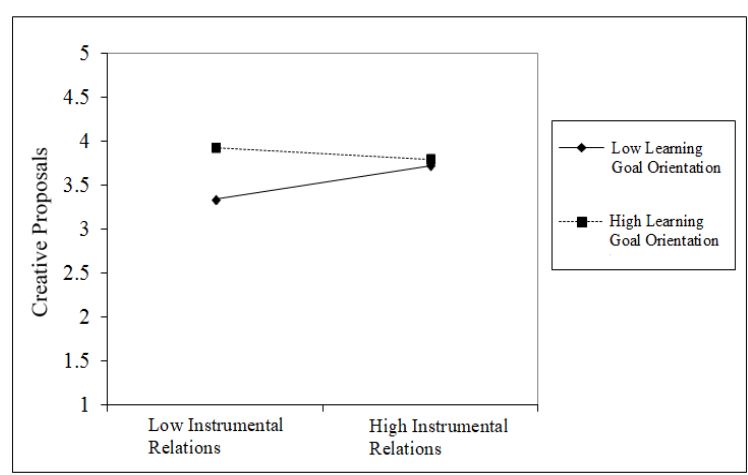

Figure 3c. Interaction effect graph of instrumental relations, learning goal orientation, and creative proposals

Figure 3: Interaction effect graph of interpersonal relations, performance goal orientation, and creative thinking 


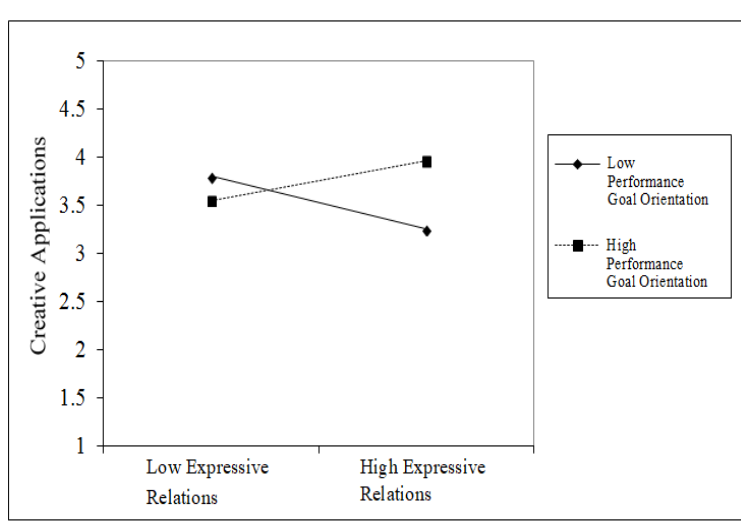

Figure 4a. Interaction effect graph of expressive relations, performance goal orientation, and creative applications

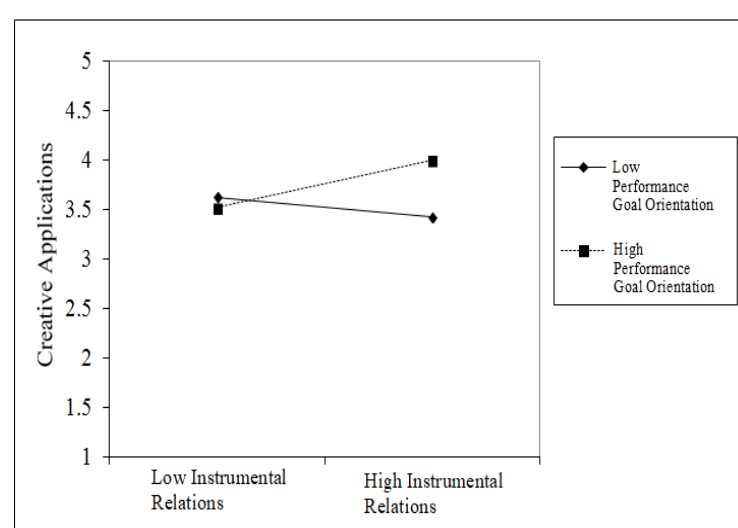

Figure 4b. Interaction effect graph of instrumental relations, performance goal orientation, and creative applications

Figure 4: Interaction effect graph of interpersonal relations, performance goal orientation, and creative thinking

\section{Conclusions and Discussion}

\subsection{Conclusions}

This study explored the effect of interpersonal relations on creative performance and how goal orientation moderates this effect. Interpersonal relations were divided into expressive and instrumental relations, and creative performance was divided into three facets, namely creative thinking, proposals, and applications. More specifically, the study examined whether expressive and instrumental relations exert different effects on these three constructs of creative performance in addition to how learning and performance goal orientations moderate these effects.

\subsubsection{Effect of Interpersonal Relations on Creative Performance}

The results indicate that strong expressive relations lead to more favorable performance in creative thinking, proposals, and applications. This phenomenon might be attributable to organization members with high expressive relations tending to maintain harmony between people, view the organization as a large family, and build trust with other members. Because such interpersonal interaction is based on emotion, organization members are likely to align their personal goals with organizational goals. When an organization's goal is to enhance creative performance, organization members intuitively endeavor toward achievement in various facets of creative performance. Accordingly, their performances in creative thinking, proposals, and applications improve. Expressive interaction might also increase the frequency of interaction, facilitating more comprehensive exchanges of knowledge or information and thereby improving creative performance. This finding is consistent with those of previous scholars (Tsai \& Ghoshal, 1998; Klein 
et al., 2004), who have indicated that when team members establish a close social network, the exchange and compilation of information between the members are improved and in turn positively affect their product innovation and value creation. When interpersonal interaction was oriented toward instrumental relations, only the creative application construct was affected. This indicates that organization members with high instrumental relations consider doing someone a favor to be a social tool. Therefore, they are active only in the application of creative ideas.

\subsubsection{Moderating Effect of Goal Orientation on the Relationship Between Interpersonal Relations and Creative Performance}

Goal orientation was divided into learning and performance goal orientations. The results reveal that learning goal orientation only exerted a moderating effect on the relationship between instrumental relations and creative proposals; this effect was not observed in the relationship between expressive relations and creative performance. Among individuals with low instrumental relations scores, those with high learning goal orientation exhibited more favorable performance in proposing creative ideas than did those with low learning goal orientation. According to the definition of learning goal orientation, highly learning goal-oriented individuals aim to improve by establishing goals to acquire knowledge. Such individuals emphasize the process of learning, deliberate on how to achieve the established goals, and attempt to complete challenging missions to improve their abilities and gain a comprehensive understanding of learning content (Dweck, 1986). When organization members exhibit high learning goal orientation, they spend much of their time learning from others while engaging in interpersonal interaction. Therefore, when their relations with other employees are less instrumental, their interaction is less complicated, which facilitates direct discussion and the sharing of information. This in turn enhances the relationship between learning goal orientation and creative proposals.

Performance goal orientation moderated the relationships between expressive relations and the three constructs of creative performance (i.e., creative thinking, proposals, and applications). Similarly, this moderating effect was observed in the relationship between instrumental relations and the three constructs. Compared with individuals with low performance goal orientation, those with high performance goal orientation demonstrated more favorable performance in creative thinking, proposals, and applications when they engaged in interaction oriented toward expressive or instrumental relations. Because employees with performance goal orientation want to prove their superiority to others, they view the work performance required by their organization as a competition, which prompts them to achieve performances required to earn supervisor recognition and receive favorable feedback and assessment scores (Steele-Johnson et al., 2000). Such employees emphasize outperforming other employees and compete against them (Janssen \& Van Yperen, 2004). Therefore, regardless of engaging in interpersonal interaction oriented toward expressive or instrumental relations, such employees endeavor to demonstrate their capability in creative thinking, proposals, and 
applications as long as these facets of creative performance align with the organization's performance goals. Accordingly, performance goal orientation enhances the relationships of expressive and instrumental relations with the various constructs of creative performance.

\subsection{Managerial Implications}

Early studies on creativity mostly focused on the effect of personal traits such as personality and motivation (Park et al., 2013). In recent years, scholars have paid closer attention to the effect of social factors on creativity. For example, PerrySmith (2006) and Perry-Smith (2014) have posited that social networks affect individual creativity. Knowledge sharing or experience acquisition through interpersonal interaction might improve creative performance. However, these topics have yet to receive the attention of scholars, constituting a gap in research. From the perspective of interpersonal relations orientations, this study explored the effect of types of interpersonal relations on creative performance to supplement said gap and to contribute to literature related to creative performance.

This study revealed that high expressive relations led to high performance in creative thinking, proposals, and applications, whereas instrumental relations affected only the application of creative ideas. Accordingly, organizations should provide members with environments that help them establish expressive relations with their colleagues. By encouraging employees to establish trusting and harmonious relationships, organizations can facilitate the exchange and integration of resources and information among employees, promote the circulation and sharing of knowledge, and positively affect employee product innovation and value creation. To achieve this, organizations can host events that facilitate employee interaction and cohesion, organize conferences for sharing knowledge and creative ideas, and prepare missions that build teamwork and trust.

We also discovered that performance goal orientation significantly moderated the effect of interpersonal relations on creative performance. Regardless of relations type, employees with favorable interpersonal relations exhibited high creative performance. Employees who are performance goal-oriented aim to compete against and surpass others (Janssen \& Van Yperen, 2004). To prove that they are superior to others, such employees view the work performance required by the organization as a competition, which motivates them to attain outstanding performance and earn recognition and favorable feedback from supervisors (SteeleJohnson et al., 2000). Performance goal-oriented individuals constantly pay attention to their performance, even when they are interacting with others. Therefore, regardless of whether an interpersonal interaction is oriented toward expressive or instrumental relations, such individuals enjoy acquiring useful knowledge or experience through the interaction to improve their creative performance. This in turn enhances the relationship between interpersonal relations and creative performance.

In addition to hosting events that promote interpersonal interaction among employees, organizations can establish incentive systems that encourage employees 
to adopt performance goal orientation. This would provide opportunities for performance goal-oriented employees to compete with others, demonstrate their ability, receive rewards and recognition, and thus improve their creative performance. For example, organizations can host creativity competitions, openly award employees with outstanding performance, and create incentive systems that encourage creative behavior. When recruiting new employees, organizations can evaluate candidates' goal orientations in addition to their competencies.

\subsection{Research Limitations and Future Research Directions}

This study had several limitations. First, the distribution of samples was limited. The samples were collected from engineers in high-tech companies who are required to demonstrate high creative performance. Although Hsinchu and Taichung contain relatively more technology companies, such companies are located throughout Taiwan. Instead of focusing their research on these two cities, future scholars can increase the scope of sampling area as well as the number of samples to improve the generalizability of the results.

Another limitation was that in addition to engineers in high-tech companies, practitioners in other areas, such as sales and marketing personnel, are required to demonstrate high creative performance in response to changes in the overall market environment. This study adopted a social perspective to explore effects on creative performance. Future research can target other industries, such as the insurance industry, that require personnel to demonstrate performance related to various social facets. Finally, the significance level adopted in this study was $p<0.1$ instead of the usual threshold of $p<0.05$. This means that the relationships between the variables observed in this study require further exploration and verification.

\section{References}

[1] Adler, P.S. and Kwon, S. (2002), "Social capital: Prospects for a new concept", Academy of Management Review, 27 (1), 17-40.

[2] Aiken, L.S. and West, S.G. (1991), "Multiple Regression: Testing and interpreting interactions", Newbury Park, CA: Sage.

[3] Amabile, T.M. (1983), "The social psychology of creativity: A componential conceptualization", Journal of Personality and social Psychology, 45 (2), 357376.

[4] Amabile, T.M. (1988), "A model of creativity and innovation in organizations," Research in Organizational Behavior, 10, 123-167.

[5] Amabile, T.M. and Gryskiewicz, S.S. (1987), Creativity in the R\&D laboratory, Technical Report Number 30. Greensboro. NC: Center for Creative Leadership.

[6] Argyris, C. and Schon, D.A. (1978), Organizational Learning: A Theory of Action Perspective, Reading, MA: Addison-Wesley.

[7] Bagozzi, R.P. and Yi, Y. (1988), "On the evaluation of structural equation models", Journal of the Academy of Marketing Science, 16(1), 74-94. 
[8] Basadur M. (1994), "Managing the creative process in organizations", in Runco, M. A. (Ed.), Problem Finding, Problem Solving, and Creativity, Norwood, NJ: Ablex, pp. 237-268.

[9] Bell, B.S. and Kozlowski, S.W.J. (2002), "Goal orientation and ability: Interactive effects on self-efficacy, performance, and knowledge," Journal of Applied Psychology, 87(3), 497-505.

[10] Browne, M.W. and Cudeck, R. (1993), "Alternative ways of assessing model fit”, in Bollen, K.A. and Long, J.S. (Eds.), Testing Structural Equation Models, pp.136-162.

[11] Button, S.B., Mathieu, J.E. and Zajac, D.M. (1996), "Goal orientation in organizational control theory: Implications for industrial and organizational psychology", in C. L. Cooper and Robertson, I.T. (Eds.), International Review of Industrial and Organizational Psychology, Vol. 8. New York: Wiley. pp. 193-232.

[12] Chang, C.H. (1998), "Education psychology: Theory and practice of educationization of research objectives", Humanization of Research Targets, and Localization of Research Methods (2nd Ed.), Taipei: Tunghua Publication.

[13] Chen, K.W. and Chen, S. (2006), "Antecedents and Performance Consequences of Salespeople's Goal Orientation," Journal of Management, 23(3), 384-411.

[14] Chou, L.F. (2007), "Guanxi and Social Network," in Cheng B.S. (Ed), Review and Prospect of Organizational Behavior Research in Taiwan in the Past 13 Years, Taipei: Laurate Publication, pp. 189-225.

[15] Dweck, C.S. (1986), "Motivational processes affecting learning. American," Psychological Association, 41(10), 1040-1048.

[16] Dweck, C. and Leggett, E. (1988), "A social-cognitive approach to motivation and personality", Psychological Review, 95, 256-273.

[17] Elliot, A.J. and Dweck, C.S. (1988), "Goal: An approach to motivation and achievement," Journal of Personality and Social Psychology, 54(1), 5-12.

[18] Farr, J.L., Hofmann, D.A. and Ringenbach, K.L. (1993), "Goal orientation and action control theory: Implications for industrial and organizational psychology," International Review of Industrial and Organizational Psychology, 8, 191-232.

[19] Fornell, C. and Larcker, D.F. (1981), "Evaluating structural equation models with unobservable variables and measurement error", Journal of Marketing Research, 18(1), 39-50

[20] George, J.M., and Zhou, J. (2001), "When openness to experience and conscientiousness are related to creative behavior: An interactional approach," Journal of Applied Psychology, 86, 513-524

[21] Gong, Y., Huang, J.C. and Farh J.L. (2009), "Employee Learning Orientation, Transformational Leadership, and Employee Creativity: The Mediating Role of Employee Creative Self-efficacy", Academy of Management Journal, 52(4), 765-778. 
[22] Gupta, V. and Singh, S. (2014), "Psychological capital as a mediator of the relationship between leadership and creative performance behaviors: empirical evidence from the Indian R\&D sector", The International Journal of Human Resource Management, 25(10), 1373-1394.

[23] Heath, R. (2001), "Shifting foundations: Public relations as relationship building", in Heath, R. (Ed.), Handbook of Public Relation, Thousand Oaks, CA: Sage.

[24] Huang, J.C. and Huang H.T. (2006), "The effect of team member goal orientation on self-efficacy, collective efficacy and innovation: A multilevel study," Journal of Management, 23(3), 327-346.

[25] Huang, K.K. (1983), Favors and reputation: Power game of Chinese people, Chinese Culture and Modernization Conference, the Chinese University of Hong Kong.

[26] Huang, K.K (1988), “Taiwanese oversea students' motives to study aboard and return to Taiwan to provide services: Effect of confucianism tradition," Academia Sinica Institute of Ethnology Journal, 66, 133-167.

[27] Hulsheger, U.R., Anderson, N. and Salgado, J.F. (2009), "Team-level predictors of innovation at work: a comprehensive meta-analysis spanning three decades of research", Journal of Applied Psychology, 94 (5), 1128-1145.

[28] Ipe, M. (2003), "Knowledge sharing in organizations: a conceptual framework", Human Resource Development Review, 2(4), 337-359.

[29] Jaccard, J., Turrisi, R. and Wan, C.K. (1990), Interaction Effects in Multiple Regression, Newbury Park, CA: Sage.

[30] Janssen, O. and Van Yperen, N.W. (2004), “Employee' goal orientations, the quality of leader- member exchange, and the outcomes of job performance and job satisfaction", Academy of Management Journal, 47(3), 368-384.

[31] Klein, K.J., Lim, B.C., Saltz, J.L. and Mayer, D.M. (2004), "How do they get there? An examination of the antecedents of centrality in team networks", Academy of Management Journal, 47(6), 952.

[32] Leung K., Chen T. and Chen G. (2014), "Learning goal orientation and creative performance: the differential mediating roles of challenge and enjoyment intrinsic motivations", Asia Pacific Journal of Management, 31(3), 811-834.

[33] Lin, C.C. and Chiu, C.C. (2004), Qualitative Research on The Types, Formation, and Interaction Content of Peer Relationships in Organizations: A Social Network Perspective, master's thesis, National Pingtung University of Science and Technology Department of Business Management.

[34] Maslow, A.H. (1943), "A theory of human motivation", Psychological review, 50(4), 370-96.

[35] Montag, T., Maertz, C.P., Jr. and Baer, M. (2012), "A critical analysis of the workplace creativity criterion space", Journal of Management, 38, 1362-1386.

[36] Oldham, G.R. and Cummings, A. (1996), "Employee creativity: Personal and contextual factors at work", Academy of Management Journal, 39, 607-634. 
[37] Park, Y.K., Song, J.H., Yoon, S.W. and Kim, J. (2013), “Learning organization and innovative behavior," European Journal of Training and Development, 38(1/2), 75 - 94.

[38] Perry-Smith, J.E. (2006), "Social yet creative: the role of social relationships in facilitating individual creativity", Academy of Management Journal, 49(1), 85-101.

[39] Perry-Smith, J.E. (2014), "Social network ties beyond nonredundancy: an experimental investigation of the effect of knowledge content and tie strength on creativity", Journal of Applied Psychology, 99(5), 831-846.

[40] Podsakoff, P.M. and Organ, D.W. (1986), "Self-Reports in organizational research: problems and prospects", Journal of Management, 12(4), 531-544.

[41] Redmond, M.R, Mumford, M.D. and Teach, R. (1993), "Putting creativity in work: Effects of leader behavior on subordinate creativity", Organizational Behavior and Human Decision Processes, 55, 120 - 151.

[42] Shalley, C.E. and Zhou, J. (2008), "Organizational creativity research: A historical overview", in Zhou J. and Shalley, C. (Eds.), Handbook of Organizational Creativity, New York: Lawrence Erlbaum and Associates, pp. 3-31.

[43] Shalley, C.E. Gilson, L. and Blum, T.C. (2000), "Matching creativity requirements and the work environment: Effects on satisfaction and intentions to leave", Academy of Management Journal, 43, 215-223.

[44] Steele-Johnson, D., Beauregard, R.S., Hoover, P.D. and Schmidt, A.M. (2000), "Goal orientation and task demand effects on motivation, affect and performance," Journal of Applied Psychology, 85, 724-738.

[45] Teng, H.C. (2007), Correlation Analysis of Motivation, Favor, and Organizational Citizenship Behavior: Moderating Role of Relationship Types, Perceived Organizational Political Climate, and Organizational Citizenship Behavior, unpublished master's thesis, National Pingtung University of Science and Technology Department of Business Management.

[46] Tierney, P. and Farmer, S.M. (2002), "Creative self-efficacy: Its potential antecedents and relationship to creative performance," Academy of Management Journal, 45, 1137-1148.

[47] Tsai, C.H. (2011), "Innovative behaviors between employment modes in knowledge intensive organizations", International Journal of Humanities and Social Science, 1(6), 153-162.

[48] Tsai, C.T. (2011), "The relationships among transformational leadership, learning goal orientation, performance goal orientation, and employee role behaviors", Journal of Management, 28 (5), 493-520.

[49] Tsai, W. and Ghoshal, S. (1998), "Social capital and value creation: The role of intrafirm networks," Academy of Management Journal, 41(4), 464-476.

[50] Vande Walle, D. (1997), "Development and validation of a work domain goal orientation instrument", Educational and Psychological Measurement, 57(6), 995-1015. 
[51] Wang, B., Zhou, H., Duan, H., Wang, X., Song, B. and Hu, W. (2020), "Highly creative individuals process creative pictorial information more effectively: Evidence from an ERP study", Creativity Research Journal, 33(2), 124-137.

[52] Wu, C. N. (2003), Research on Organizational Culture, Climate, and Citizenship Behavior, unpublished master's thesis, Chang Yuan Christian University Department of Psychology.

[53] Yang, C. F. (1999), "Conceptualization of interpersonal relationships and emotion”, Domestic Psychology Research, 12, 105-179. 